\title{
Autophagy is increased following either pharmacological or genetic silencing of mGluR5 signaling in Alzheimer's disease mouse models
}

\author{
Khaled S. Abd-Elrahman ${ }^{1,2,3^{\dagger}}$, Alison Hamilton ${ }^{1,2 \dagger}$, Maryam Vasefi ${ }^{4}$ and Stephen S. G. Ferguson ${ }^{1,2^{*}}$ (1)
}

\begin{abstract}
Alzheimer's disease (AD) is characterized by neurotoxicity mediated by the accumulation of beta amyloid (Aß) oligomers, causing neuronal loss and progressive cognitive decline. Genetic deletion or chronic pharmacological inhibition of mGluR5 by the negative allosteric modulator CTEP, rescues cognitive function and reduces A $\beta$ aggregation in both APPswe/PS1 $\triangle E 9$ and 3xTg-AD mouse models of AD. In late onset neurodegenerative diseases, such as $A D$, defects arise at different stages of the autophagy pathway. Here, we show that mGluR5 cell surface expression is elevated in APPswe/PS1 $\triangle$ E9 and 3xTg-AD mice. This is accompanied by reduced autophagy (accumulation of p62) as the consequence of increased ZBTB16 expression and reduced ULK1 activity, as we have previously observed in Huntington's disease (HD). The chronic (12 week) inhibition of mGluR5 with CTEP in APPswe/PS1 $\triangle E 9$ and 3xTg-AD mice prevents the observed increase in mGluR5 surface expression. In addition, mGluR5 inactivation facilitates the loss of ZBTB16 expression and ULK1 activation as a consequence of ULK-Ser757 dephosphorylation, which promotes the loss of expression of the autophagy marker p62. Moreover, the genetic ablation of mGluR5 in APPswe/PS1 $\triangle$ E9 mice activated autophagy via similar mechanisms to pharmacological blockade. This study provides further evidence that mGluR5 overactivation contributes to inhibition of autophagy and can result in impaired clearance of neurotoxic aggregates in multiple neurodegenerative diseases. Thus, it provides additional support for the potential of MGluR5 inhibition as a general therapeutic strategy for neurodegenerative diseases such as AD and HD.
\end{abstract}

Keywords: GPCR, mGluR5, Alzheimer's disease, APPswe/PS1 AE9, 3xTg-AD, CTEP, ULK1, ZBTB16, Autophagy

\section{Introduction}

Alzheimer's disease (AD) is the most prevalent of all the neurodegenerative diseases, with an alarming rise in prevalence as a result of an aging population [1]. AD presents as progressive memory loss and cognitive decline and current therapeutic strategies are not curative with limited efficacy $[2,3]$. Beta-amyloid $(A \beta)$ protein, a product of amyloid precursor proteins (APP) cleavage that forms soluble oligomers and fibrillar

\footnotetext{
* Correspondence: sferguso@uottawa.ca

${ }^{\dagger}$ Equal contributors

'University of Ottawa Brain and Mind Institute, University of Ottawa, 451 Smyth Road, Ottawa, ON K1H 8M5, Canada

${ }^{2}$ Department of Cellular and Molecular Medicine, University of Ottawa, 451

Smyth Road, Ottawa, ON K1H 8M5, Canada

Full list of author information is available at the end of the article
}

plaques, is considered the principal neurotoxic species in $\mathrm{AD}$ brains along with neurofibirillary tangles comprised of phosphorylated Tau protein [4-6].

Metabotropic glutamate receptor 5 (mGluR5) is a member of the $G$ protein-coupled receptor (GPCR) superfamily and when activated by glutamate couples to the heterotrimeric $G$ protein $G \alpha_{q / 11}$ [7]. mGluR5 also functions as an extracellular scaffold for $A \beta$ oligomers. Activation of mGluR5 by $A \beta$ oligomers leads to the release of $\mathrm{Ca}^{2+}$ from intracellular stores and a consequent disruption in synaptic signaling and function [8-10]. We have shown that the genetic deletion of mGluR5 in the APPswe/PS1 $\triangle E$ 9 (APPswe) mouse model of AD improved cognitive function and reduced $A D$ pathogenesis [11]. Moreover, the pharmacological 
blockade of mGluR5 using the mGluR5-selective negative allosteric modulator CTEP, reduces the development of AD-like neuropathology; specifically reducing $A \beta$ soluble oligomer and plaque deposition, in both APPswe/ PS1 $\triangle \mathrm{E} 9$ and 3xTg-AD (3xTg) mouse models [12]. Similarly, mGluR5 knockout and pharmacological blockade results in delayed disease progression and a reduction in huntingtin pathology in preclinical mouse models of Huntington's disease (HD) which we have linked to increased autophagy via alterations in both Zinc finger and BTB domain-containing protein 16 (ZBTB16)- and Unc-51-like kinase 1 (ULK1)-dependent mechanisms $[13,14]$. Specifically, we showed that pharmacological blockade of mGluR5 in HD mice reduced the expression of ZBTB16, key component of the ZBTB16-Cullin3Roc1 E3-ubiquitin ligase complex, leading to rescue of the key autophagy adaptor ATG14. mGluR5 inhibition also activated ULK1 that was essential for phosphorylation of the autophagy factor ATG13, required for autophagosome formation [14, 15]. However, it remains unclear whether alterations in these autophagy pathways due to aberrant mGluR5 signaling are also evident in mouse models of AD.

Here, we show that the reduction in $A \beta$ burden and improvement in memory function following mGluR5 pharmacological antagonism or genetic knockout in APPswe mice $[11,12]$, is paralleled by a reduction of increased cell surface mGluR5 expression in APPswe and $3 \times T g$ mice as well as the reduction of the autophagy marker p62 as the consequence of reduced ZBTB16 expression and increased ULK1 activity. These findings using two different approaches to silence mGluR5 as well as two different mouse models of AD further support the pivotal role of mGluR5 in AD pathogenesis.

\section{Results}

Chronic mGluR5 antagonism reduces mGluR5 cell surface expression in AD mouse models

$A \beta$ oligomers were previously reported to activate mGluR5 and trigger their clustering, thereby contributing to the glutamate excitotoxicity at the neuronal synapses in the AD brain [8-10]. We have also reported an elevated mGluR5 cell surface expression in 12month-old APPswe mice. Here, we tested whether elevated mGluR5 cell surface expression contribute to $A D$ pathology in another AD model, the $3 \times \mathrm{Tg}$ mouse model. We also examined whether chronic (12-week) inhibition of mGluR5 using CTEP $(2 \mathrm{mg} / \mathrm{kg})$ in 9-month-old APPswe and 3xTg mice could normalize mGluR5 cell surface expression and, thereby might contribute to the favorable outcome of mGluR5 inhibition on cognitive function in both mouse models. The highly potent mGluR5-speciific negative allosteric modulator CTEP (2-chloro-4-[2[2,5-dimethyl-1-[4-(trifluoromethoxy) phenyl] imidazol-4-yl] ethynyl] pyridine) was chosen for this study because it is orally bioavailable, crosses the blood brain barrier, has a half-life of $18 \mathrm{~h}$ and its analogue, Basimglurant, was proven to be well- tolerated in phase II trials for major depressive disorder [16, 17]. Coronal brain slices from 12-month-old APPswe, 3xTg and control mice (C59Bl/6 for APPswe and B6129sf for $3 x \mathrm{Tg}$ ) after 12 weeks of intraperitoneal injection with either CTEP or saline were employed in a cell surface biotinylation assay to determine total and cell membrane expression of mGluR5. We detected an increase in the cell surface expression of mGluR5 in the brain slices from saline-treated APPswe and 3xTg brains when compared to wild-type mice (Fig. 1a, b, d and e). Interestingly, the increase in mGluR5 surface expression was reversed in CTEP-treated AD mice and the values were indistinguishable from controls. No significant change in the total expression of mGluR5 was detected in all groups (Fig. 1c and $\mathrm{f}$ ). Taken together, these results indicated that chronic antagonism of mGluR5 with a selective negative allosteric modulator (NAM) could block the increase in cell surface expression of mGluR5 and thus may contribute to slowing the progression AD pathology and improvement in cognitive function.

\section{Pharmacological and genetic silencing of mGluR5 activate autophagy via a ZBTB16-regulated pathway}

Zhang and colleagues reported a novel pathway through which GPCR signaling inhibits autophagy. Specifically, GPCR activation stabilized the expression of the transcription factor ZBTB16, a key component of the ZBTB16-Cullin3-Roc1 E3-ubiquitin ligase, which promoted the degradation of various autophagy adaptor proteins to inhibit autophagy [18]. Therefore, we wanted to determine whether silencing mGluR5 signaling either pharmacologically or genetically would reduce ZBTB16 expression in $3 x \mathrm{Tg}$ and APPswe mice to activate autophagy. We examined brain lysates derived from 12month old mice APPswe after 12-week treatment with either CTEP or saline as well as age-matched APPswe lacking mGluR5 (APPswe/mGluR $5^{--}$). We found that the expression of the ubiquitin ligase component ZBTB16 and the autophagy marker p62 were increased in both saline-treated 3xTg and APPswe mice and that chronic treatment of these mice with CTEP for 12 weeks reduced both ZBTB16 and p62 protein expression to values comparable to wild-type control mice (Fig. $2 \mathrm{a}$ and b). We also detected a reduction in p62 and ZBTB16 expression in APPswe/mGluR5 ${ }^{-/-}$and significantly lower levels of ZBTB16 in mGluR5 ${ }^{-/-}$compared to wild-type $\mathrm{C} 57 \mathrm{Bl} / 6$ mice (Fig. 2c). Taken together, these data indicate an obligatory role of mGluR5 in ZBTB16regulated activation of autophagy. 


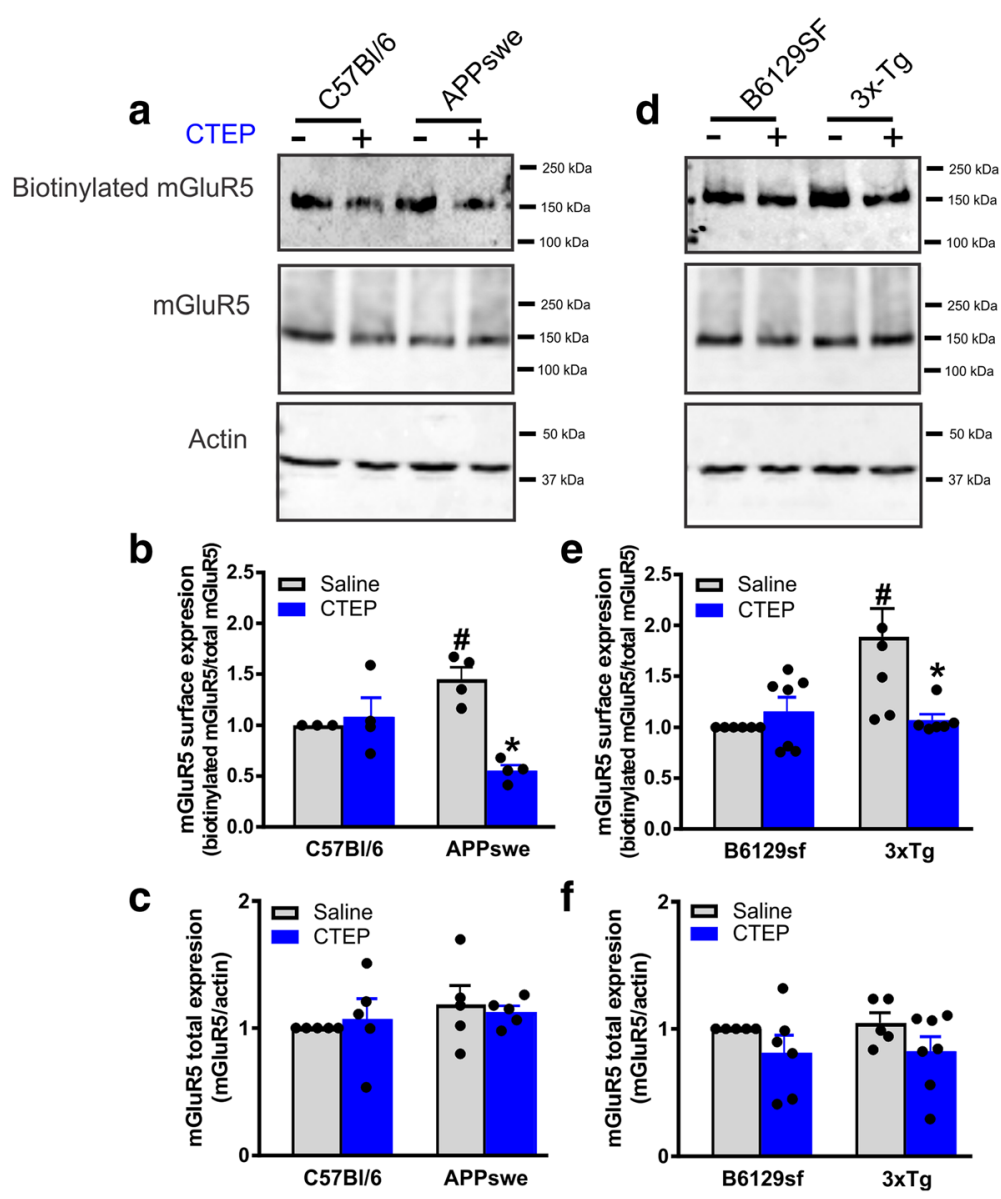

Fig. 1 CTEP reduces surface but not total expression of mGluR5 in AD mice. a Representative western blots and mean \pm SEM of mGluR5 surface expression $\mathbf{b}$ and total expression $\mathbf{c}$ in brain lysates from APPswe/PS1 $\triangle E 9$ (APPswe) and C57BI/6 controls mice after chronic treatment with either saline or CTEP $(2 \mathrm{mg} / \mathrm{kg})$. d Representative western blots and mean \pm SEM of mGluR5 surface expression e and total expression $\mathbf{f}$ in brain lysates from 3xTg-AD (3xTg) and B6129sf control mice after chronic treatment with either saline or CTEP. Values are expressed as a fraction of the salinetreated control. Surface expression represents quantification of biotinylated mGluR5 relative to total mGluR5 expression. Total mGluR5 expression was normalized to actin ( $n=4-6$ for each group). \# Significantly different $(P<0.05)$ from corresponding C57B6/l or B6129sf values, * significantly different $(P<0.05)$ from saline-treated value

\section{Pharmacological and genetic silencing of mGluR5 activates ULK1}

ULK family members are ubiquitously expressed kinases that localize to the phagophore membrane upon nutrient starvation to promote autophagosome formation $[19,20]$. mTOR phosphorylates ULK1 at Ser757 suppressing its kinase activity and autophagy initiation [15]. mGluR5 is known to activate the mTOR pathway and it reduced ULK1-dependent activation of autophagy in zQ175 HD mice $[14,21]$. Here, we tested whether blocking mGluR5 could induce autophagy by activating ULK1 dephosphorylation in 3xTg and APPswe mouse models of AD. Chronic blockade of mGluR5 with CTEP reduced the inhibitory phosphorylation of ULK1 at Ser757 observed in saline-treated $3 x \mathrm{Tg}$ and APPswe mice (Fig. $3 \mathrm{a}$ and $\mathrm{b}$ ) to values comparable to corresponding wild-type levels indicating an increase in ULK1 activity following CTEP treatment. Interestingly, genetic deletion of mGluR5 completely abolished ULK1-Ser757 phosphorylation in wild-type and APPswe mice (Fig. 3c). Together, these findings strongly support the role of ULK1 in mGluR5-mediated regulation of autophagy and that mGluR5 can potentially alter autophagy via multiple convergent mechanisms and this correlates with the clearance of proteotoxic aggregates, in this case $\beta$-amyloid plaques.

\section{Discussion}

mGluR5 antagonism using highly-selective mGluR5 NAMs represents a promising approach to slow disease progression and proteotoxic protein aggregation in both $\mathrm{AD}$ and HD $[12,14]$. In the current study, we provide further evidence for the pivotal role of mGluR5 in AD 


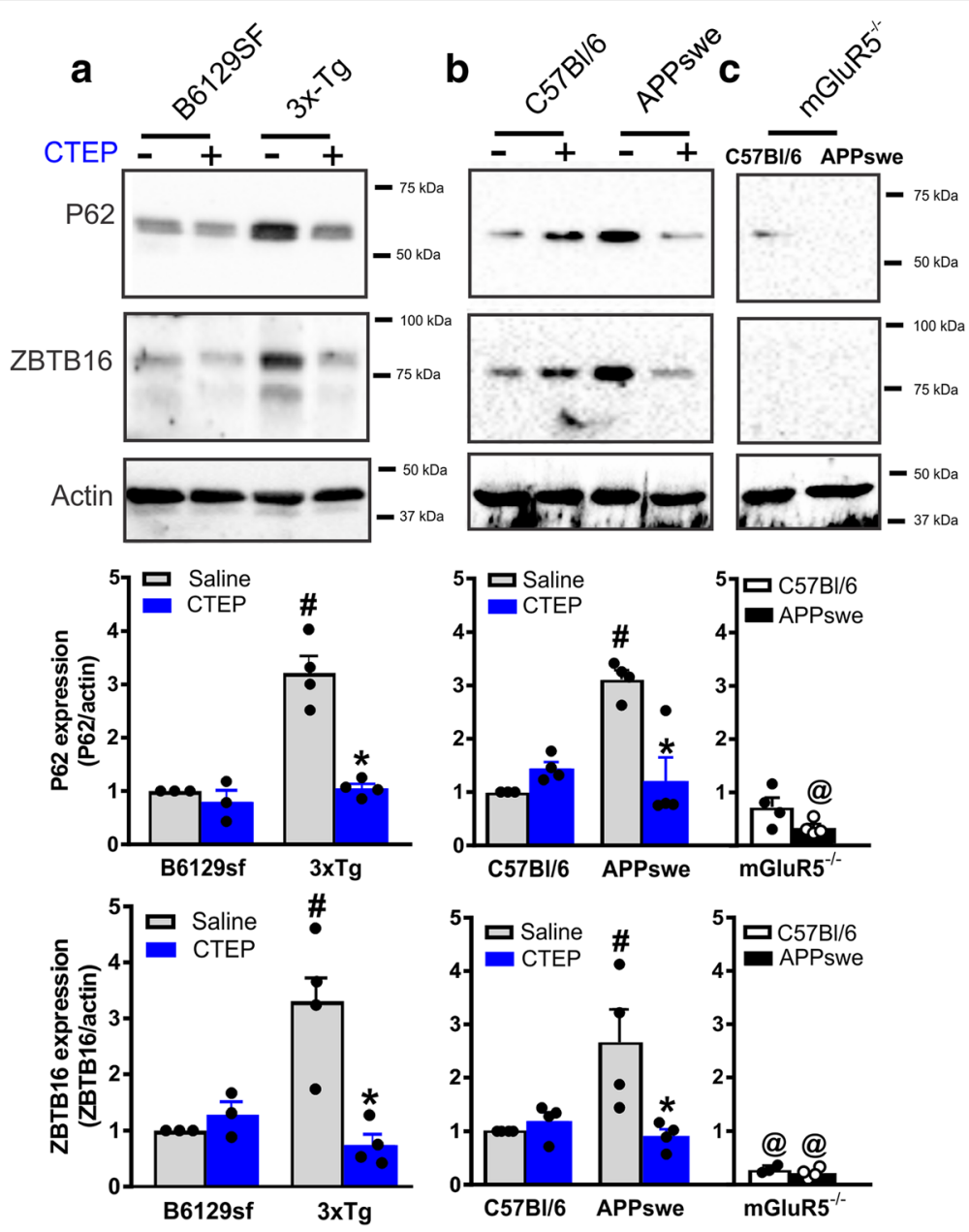

Fig. 2 ZBTB16-mediated activation of autophagy in AD mice is mGluR5-dependent. a Representative western blots and mean \pm SEM of P62 and ZBTB16 in brain lysates from 3xTg-AD (3xTg) and control B6129sf mice after chronic treatment with either saline or CTEP (2 mg/kg). b Representative western blots and mean \pm SEM of P62 and ZBTB16 in brain lysates from APPswe/PS1 $\triangle E 9$ (APPswe) and control C56BI/6 mice after chronic treatment with either saline or CTEP or c genetic deletion of mGluR5 $\left(\mathrm{mGluR5^{-1 }}{ }^{-}\right.$). Representative Blots in panel from B and C are from the same blot. Values are expressed as a fraction of the saline-treated control. ZBTB16, and P62 are normalized to actin ( $n=4$ for each group). \# Significantly different $(P<0.05)$ from corresponding control for each AD mouse model, ${ }^{*}$ significantly different $(P<0.05)$ from saline-treated value. @ significantly different $(P<0.05)$ from saline treated C57BI/6 or APPswe

pathogenesis by demonstrating an increase in mGluR5 surface expression in two AD mouse models, the APPswe and $3 \times \mathrm{Tg}$ models. We also show for, the first time, that the mGluR5 NAM CTEP could abolish the increase in membrane delivery of mGluR5 that is correlated with an activation of autophagy via a ZBTB16- and ULK1- dependent pathways in both mouse models of AD. Moreover, the genetic deletion of mGluR5 in APPswe resulted in similar outcomes to the pharmacological inhibition with a mGluR5 NAM and further supports the role of mGluR5mediated regulation of autophagy in the pathology of AD. The observation that this molecular pathway is similarly activated in a zQ175 mouse model of HD following treatment with the mGluR5 NAM, CTEP [14], indicates that mGluR5 contributes neurodegenerative disease processes via a conserved mechanism.
This study extends our previous work using both genetic and pharmacological approaches to implicate mGluR5 in the pathophysiological hallmarks of AD. We reported that the pharmacological inhibition and genetic ablation of mGluR5 corrected spatial memory loss and reduced formation of $\mathrm{A} \beta$ oligomers and plaques in $\mathrm{AD}$ mice $[11,12]$. Here, we provide further evidence for the role of mGluR5 signaling in AD by demonstrating an increase in the delivery of mGluR5 to the plasma membrane in brain slices derived from both APPswe and $3 \times \mathrm{Tg}$ mice mouse models of $\mathrm{AD}$. The increase in mGluR5 surface expression is particularly interesting as $\mathrm{A} \beta$ oligomers interact with mGluR5 and potentially functions to accelerate $A \beta$ production via the mGluR5- and Fragile $\mathrm{X}$ mental retardation protein (FMRP)-dependent activation of the amyloidogenic pathway $[10,11]$. These $A \beta$ 


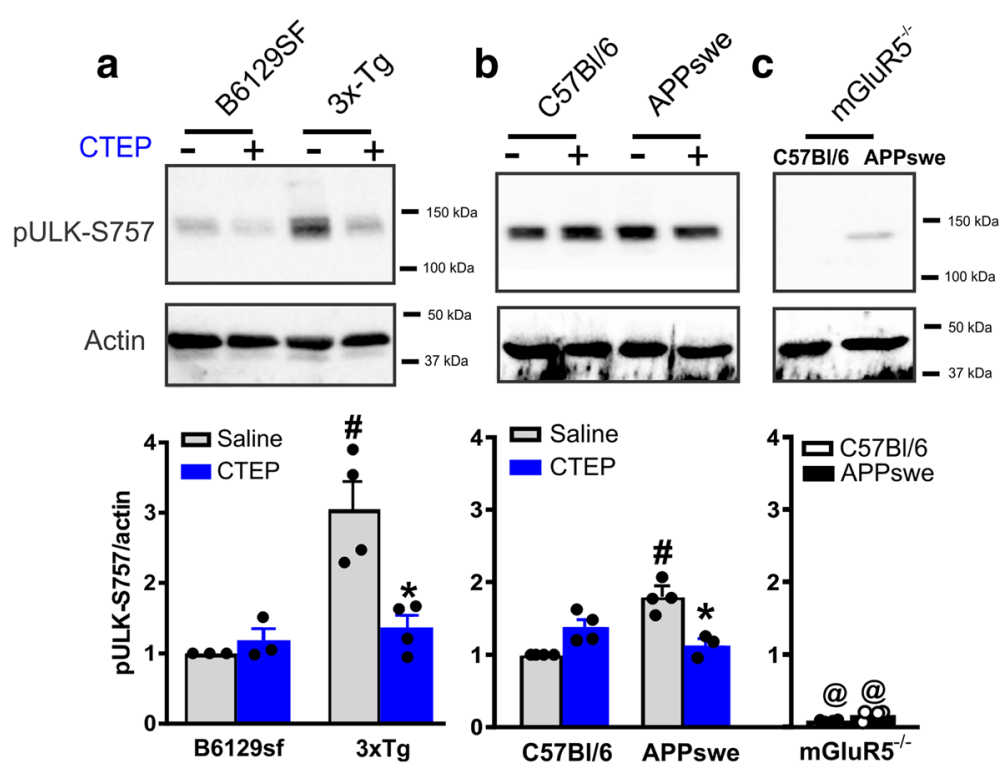

Fig. 3 ULK1 activation plays a role in mGluR5-dependent activation of autophagy in AD mice. a Representative western blots and mean \pm SEM of pULKSer757 in brain lysates from 3xTg-AD (3xTg) and control B6129sf mice after chronic treatment with either saline or CTEP (2 mg/kg). b Representative western blots and mean \pm SEM of pULK-Ser757 in brain lysates from APPswe/PS1 $\triangle E 9$ (APPswe) and control C56Bl/6 mice after chronic treatment with either saline or CTEP or c genetic deletion of mGluR5 ( $\mathrm{mGluR5}^{-1}$ ). Representative Blots in panel from B and C are from the same blot. Values are expressed as a fraction of the saline-treated control. pULK-Ser757 is normalized to actin ( $n=4$ for each group). \# Significantly different $(P<0.05)$ from corresponding control for each AD mouse model, * significantly different $(P<0.05)$ from saline-treated value. @ significantly different $(P<0.05)$ from saline treated C57Bl/6 or APPswe

oligomers also trigger the clustering and activation of mGluR5 resulting in the release of $\mathrm{Ca}^{2+}$ from intracellular stores, an event that is critical for the neurotoxic signaling at glutamatergic synapses $[8,9]$. The enhanced delivery of mGluR5 means that the receptor is more readily accessible for activation and clustering by $A \beta$ oligomers, thereby potentially accelerating glutamatergic excitotoxicity, synaptic loss and $\mathrm{AD}$ progression. Thus, CTEP via its allosteric binding to mGluR5 may function to disrupt a proposed $A \beta$ oligomer-mediated neurodegenerative positive feedback loop. The disruption of this feedback loop may contribute in part to a reduction in the formation of $A \beta$ oligomers and plaques resulting in improvement in memory and cognitive function. Our findings support a critical/ central contribution of pathological mGluR5 signaling to the pathophysiology underlying $\mathrm{AD}$.

Studies using transgenic mice with impaired central nervous system autophagy reported an increase in ubiquitinated protein inclusions and neurodegeneration [22, 23]. This observation strongly suggests an obligatory role of autophagy in neuronal health. Autophagy is a catabolic process that clears cellular organelles and protein aggregates and defects in autophagy have been increasingly implicated in proteinopathies such as AD, HD and Parkinson's disease [24-27]. We have demonstrated that mGluR5 signals through a ZBTB16-Cullin3-Roc1 E3ubiquitin ligase pathway to inhibit autophagy in a zQ175 HD mouse model, which we have correlated with the accumulation of mutant huntingtin aggregates and disease progression. mGluR5 blockade with CTEP triggers the degradation of ZBTB16 to rescue autophagy adaptor protein ATG14 and activates autophagy that is associated with a reduction in mutant huntingtin aggregation. Moreover, mGluR5 blockade reduces ULK1-Ser757 phosphorylation and to allow autophagy adaptorinitiated autophagosome biogenesis [14]. Similar to HD mice, in the study we detect a significant elevation in ZBTB16 and p62 expression, as well as ULK1-Ser757 phosphorylation in both APPswe and $3 \mathrm{X}-\mathrm{Tg}$ mice that is significantly attenuated following CTEP treatment. In addition, we also employ an alternative approach to knockout mGluR5 in APPswe via the genetic deletion of mGluR5. This resulted in an even more robust reduction in ZBTB16, P62 and pULK1-Ser757 phosphorylation levels compared to the pharmacological approach. These findings along with our previous reports showing a reduction $A \beta$ oligomers and plaques $[11,12]$ indicates that mGluR5 signaling via ZBTB16 and ULK1 is crucial to maintain adequate clearance of these proteotoxic aggregates. Thus, alterations in mGluR5-mediated signaling in the brain is expected to accelerate the process of neurodegeneration in $\mathrm{AD}$.

In summary, we find that mGluR5 antagonism represents an effective approach to slow and potentially reverse $A D$ progression both at the receptor level, by reducing mGluR5 membrane trafficking, and at the 
signaling level, by activating autophagy. Moreover, findings from this study and our previous work in zQ175 HD mice [14] provide evidence to support a conserved mechanism of autophagy inhibition downstream of mGluR5 that potentially reduces the clearance of toxic misfolded protein species in both $\mathrm{AD}$ and HD. This study also extends on our previous observations that pharmacologically targeting a single GPCR may be effective in clearing neurotoxic aggregates through autophagy via a well-tolerated novel therapeutic approach. These findings warrant further investigation of the role of ZBTB16- and mTOR-mediated autophagic pathway in other neurodevelopmental and neurodegenerative diseases in which mGluR5 has been previously implicated $[28,29]$. This will provide a better understanding of the common pathophysiological signals in neurodegeneration and ultimately novel therapeutic approaches to target these aberrant signals.

\section{Materials and methods Reagents}

CTEP was purchased from Axon Medchem. Horseradish peroxidase (HRP)-conjugated anti-rabbit IgG secondary antibody was from Bio-Rad(1662408EDU). Rabbit antiactin (CL2810AP) was from Cedarlane (Burlington, Ontario). Mouse anti-P62 (56416) and rabbit antiZBTB16 (39354) antibodies were from Abcam (Cambridge, Massachusetts). Rabbit anti-mGluR5 antibody (AB5675) was from Millipore (Billerica, Massachusetts). Anti-phospho ULK1-Ser ${ }^{757}$ (14202) from Cell Signaling Technology (Danvers, Massachusetts). Reagents used for western blotting were purchased from (Bio-Rad Laboratories, Hercules, California) and all other biochemical reagents were from Sigma-Aldrich (St. Louis, Missouri).

\section{Animals}

STOCK B6C3-Tg (APPswe/PSEN1 $\triangle E$ 9)85Dbo/J mice that carry the human APP with Swedish mutation and the DeltaE9 mutation of the human presenilin 1 gene [30], mGluR5 knockout mice B6;129-Grm5tm1Rod/J $\left(\mathrm{mGluR5}^{-/-}\right)$[31] and 3xTg-AD mice that carry both the human APP with Swedish mutation and the DeltaE9 mutation of the human presenilin 1 gene along with a tau P301L mutation [32] were purchased from Jackson Laboratory (Bar Harbor, ME). APPswe/PS1 $\triangle \mathrm{E} 9$ / mGluR5 $^{-/-}$mice were generated by crossing APPswe/ $\mathrm{PS} 1 \triangle \mathrm{E} 9$ mice with a C57/B16 background, with mGluR5 ${ }^{-1-} \mathrm{C} 57 \mathrm{Bl} / 6$ females. Offspring were tail snipped and genotyped using PCR with primers specific for the APP sequence and primers specific for mGluR5. Animals were housed in an animal care facility in cages of 2 or more animals, received food and water ad libitum and were maintained on a 12-h light/12 h dark cycle at $24{ }^{\circ} \mathrm{C}$. Two sets of male APPswe/PSEN1 $\Delta \mathrm{E} 9$, $3 x T g-A D$ mice and their wild-type control mice (C57Bl/ 6 control for APPswe and B6129sf control for 3xTg) were aged to 9 months and were then treated by intraperitoneal injection with a $200 \mu \mathrm{l}$ volume of either vehicle (saline control) or CTEP (2 $\mathrm{mg} / \mathrm{kg}$, final concentration $20 \mathrm{nM}$ ) every $48 \mathrm{~h}$ for 12 weeks by a blinded technician. At the end of the 12-week treatment, mice were sacrificed by exsanguination and brains were collected and randomized for biochemical determinations. $\mathrm{mGluR}^{-/-}$and APPswe/PS1 $\triangle \mathrm{E} 9 / \mathrm{mGluR}^{-/-}$mice were aged to 12 months and sacrificed by exsanguination and brains were collected for biochemical determinations.

\section{Cell surface biotinylation}

Cell surface biotinylation was performed as previously described $[7,11]$. Coronal brain slices $(350 \mu \mathrm{m})$ from saline- or CTEP-treated wild-type, APPswe and 3xTg mice were prepared using a vibratome system (Leica). Slices were recovered in KREBS buffer $(127 \mathrm{mM} \mathrm{NaCl}, 2 \mathrm{mM}$

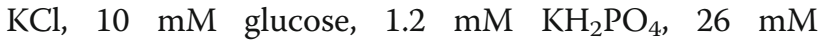
$\mathrm{NaH}_{2} \mathrm{CO}_{3}, 1 \mathrm{mM} \mathrm{MgSO}, 1 \mathrm{mM} \mathrm{CaCl} 2, \mathrm{pH}$ 7.4) continuously gassed with $95 \% \mathrm{O}_{2} / 5 \% \mathrm{CO}_{2}$ for 30 min at $37^{\circ}$ C. Slices were transferred to tubes and biotinylated for $1 \mathrm{~h}$ in $1.5 \mathrm{mg} / \mathrm{ml}$ sulfo-NHS-SS-biotin on ice. Slices were then washed and biotinylation was quenched with $100 \mu \mathrm{M}$ glycine in HBSS for $30 \mathrm{~min}$ on ice. Following washes in HBSS, tissue was lysed in RIPA buffer $(0.15 \mathrm{M}$ $\mathrm{NaCl}, 0.05 \mathrm{M}$ Tris-HCl, pH 7.2, 0.05 M EDTA, 1\% Nonidet P40, 1\% Triton X-100, 0.5\% sodium deoxycholate, 0 . $1 \%$ SDS) containing protease inhibitors (1 mM AEBSF, $10 \mu \mathrm{g} / \mathrm{ml}$ leupeptin, and $2.5 \mu \mathrm{g} / \mathrm{ml}$ aprotinin). Biotinylated proteins were then precipitated with NeutrAvidin beads using equivalent amounts of proteins for each sample. Biotinylated proteins were subjected to SDSpolyacrylamide gel (SDS-PAGE) and immunoblotted with Rabbit polyclonal mGluR5 antibody (1:1000, dilution), as described below.

\section{Immunoblotting}

Brain hemispheres was lysed in $1.5 \mathrm{ml}$ ice-cold lysis buffer $(50 \mathrm{mM}$ Tris, $\mathrm{pH} 8.0,150 \mathrm{mM} \mathrm{NaCl}$, and $1 \%$ Triton $\mathrm{X}-100)$ containing protease inhibitors (1 mM AEBSF, 10 $\mu \mathrm{g} / \mathrm{ml}$ leupeptin, and $2.5 \mu \mathrm{g} / \mathrm{ml}$ aprotinin) and phosphatase inhibitors $\left(10 \mathrm{mM} \mathrm{NaF}\right.$ and $\left.500 \mu \mathrm{M} \mathrm{Na} \mathrm{NO}_{4}\right)$ and centrifuged at $15000 \mathrm{rpm}$ at $4{ }^{\circ} \mathrm{C}$ for $15 \mathrm{~min}$. The supernatant was collected and total protein levels were quantified using Bradford Protein Assay (Bio-Rad). Homogenates were diluted in a mix of lysis buffer and $\beta$-mercaptoethanol containing $3 \times$ loading buffer and boiled for $10 \mathrm{~min}$ at $95{ }^{\circ} \mathrm{C}$. Aliquots containing $25 \mu \mathrm{g}$ total proteins were resolved by electrophoresis on a 7.5\% SDS-PAGE and transferred onto nitrocellulose 
membranes. Blots were blocked in Tris-buffered saline, $\mathrm{pH} 7.6$ containing $0.05 \%$ of Tween 20 (TBST) and 5\% non-fat dry milk for $2 \mathrm{~h}$ at room temperature and then incubated overnight at $4{ }^{\circ} \mathrm{C}$ with primary antibodies diluted 1:1000 in TBST containing 1\% non-fat dry milk. Immunodetection was performed by incubating with secondary antibodies (anti-rabbit/mouse) diluted 1:5000 in TBST containing $1 \%$ of non-fat dry milk for $1 \mathrm{~h}$. Membranes were washed in TBST and then bands were detected and quantified using BioRad chemiluminescence system.

\section{Statistical analysis}

Means \pm SEM are shown for each of independent experiments are shown in the various figure legends. GraphPad Prism software was used to analyze data for statistical significance. Statistical significance was determined by a series of 2 (strain) $\times 2$ (drug treatment) ANOVAs followed by Fisher's LSD comparisons for the significant main effects or interactions.

\begin{abstract}
Abbreviations
3xTg: 3xTg-AD; AD: Alzheimer's disease; APP: Amyloid precursor protein; APPswe: APPswe/PS1 $\Delta$ E9; APPswe/ mGluR5 ${ }^{-/-}$: APPswe/PS1 $\Delta$ E9 lacking mGluR5; ATG14: Autophagy-related protein 14; A 3 : Amyloid beta; CTEP: 2chloro-4-[2[2,5-dimethyl-1-[4-(trifluoromethoxy) phenyl] imidazol-4-yl] ethynyl] pyridine; FMRP: Fragile X mental retardation protein; GPCR: G proteincoupled receptor; HD: Huntington's disease; mGluR5: metabotropic glutamate receptor 5; mTOR: mammalian target of rapamycin; NAM: Negative allosteric modulator; ULK: Unc-51-like kinase; ZBTB16: Zinc finger and BTB domain-containing protein 16
\end{abstract}

\section{Acknowledgements}

S.S.G.F holds a Tier I Canada Research Chair in Brain and Mind. K.S.A is a Lecturer in the Department of Pharmacology \& Toxicology, Faculty of Pharmacy, University of Alexandria, Egypt. Thanks to Cheryl Vander Tuin for breeding and drugging colonies.

\section{Funding}

This study was supported by the Huntington's Society of Canada and Canadian Institutes for Health Research (CIHR) grant (MOP 119437) to S.S.G.F, and clinician postdoctoral fellowship from the Alberta Innovates Health Solutions and CIHR to K.S.A.

\section{Availability of data and materials}

All data generated or analyzed during this study are included in this published article.

\section{Authors' contributions \\ KSA, AH and SSGF were responsible for the conception and design of all experiments. KSA, AH and MV performed the experiments. KSA, MV and SSGF analyzed the data. KSA and SSGF wrote the manuscript and SSGF supervised the study. All authors read and approved the final manuscript.}

\section{Ethics approval}

All animal experiments were conducted in accordance with the University of Western Ontario and University of Ottawa animal care committees.

\section{Consent for publication}

Not applicable.

\section{Competing interests}

The authors declare that they have no competing interests.

\section{Publisher's Note}

Springer Nature remains neutral with regard to jurisdictional claims in published maps and institutional affiliations.

\section{Author details}

'University of Ottawa Brain and Mind Institute, University of Ottawa, 451 Smyth Road, Ottawa, ON K1H 8M5, Canada. ${ }^{2}$ Department of Cellular and Molecular Medicine, University of Ottawa, 451 Smyth Road, Ottawa, ON K1H 8M5, Canada. ${ }^{3}$ Department of Pharmacology and Toxicology, Faculty of Pharmacy, University of Alexandria, Alexandria 21521, Egypt. ${ }^{4}$ Lamar University, Beaumont, TX 77710, USA.

Received: 8 March 2018 Accepted: 28 March 2018

Published online: 10 April 2018

References

1. Alzheimer's Association. 2016 Alzheimer's disease facts and figures. Alzheimers Dement. 2016;12:459-509. [cited 2017 Nov 16] Available from: http://www.ncbi.nlm.nih.gov/pubmed/27570871

2. Casey DA, Antimisiaris D, O'Brien J. Drugs for Alzheimer's disease: are they effective? P T. 2010;35:208-11. [cited 2017 Nov 16] Available from: http:// www.ncbi.nlm.nih.gov/pubmed/20498822. MediMedia, USA

3. Lanctôt KL, Rajaram RD, Herrmann N. Therapy for Alzheimer's disease: how effective are current treatments? Ther Adv Neurol Disord. 2009;2:163-80. [cited 2017 Nov 16] Available from: http://wwew.ncbi.nlm.nih.gov/pubmed/ 21179526. SAGE Publications

4. Hunter S, Brayne C. Understanding the roles of mutations in the amyloid precursor protein in Alzheimer disease. Mol Psychiatry. 2017; [cited 2017 Nov 16] Available from: http://www.ncbi.nlm.nih.gov/pubmed/29112196

5. Kamenetz F, Tomita T, Hsieh H, Seabrook G, Borchelt D, Iwatsubo T, et al. APP processing and synaptic function. Neuron. 2003;37:925-937. [cited 2017 Nov 16] Available from: http://www.ncbi.nlm.nih.gov/pubmed/12670422.

6. Hamilton A, Zamponi GW, SSG F. Glutamate receptors function as scaffolds for the regulation of $\beta$-amyloid and cellular prion protein signaling complexes. Mol Brain. 2015;8:18. [cited 2017 Nov 15] Available from: http:// www.molecularbrain.com/content/8/1/18

7. Ribeiro FM, Paquet M, Ferreira LT, Cregan T, Swan P, Cregan SP, et al. Metabotropic glutamate receptor-mediated cell signaling pathways are altered in a mouse model of Huntington's disease. J Neurosci. 2010;30:316-24. [cited 2016 Oct 20] Available from: http://www.ncbi.nlm.nih.gov/pubmed/20053912

8. Um JW, Kaufman AC, Kostylev M, Heiss JK, Stagi M, Takahashi H, et al. Metabotropic glutamate receptor 5 is a Coreceptor for Alzheimer $A \beta$ oligomer bound to cellular prion protein. Neuron. 2013;79:887-902. [cited 2016 Nov 15] Available from: http://linkinghub.elsevier.com/retrieve/pii/S0896627313005527

9. Renner M, Lacor PN, Velasco PT, Xu J, Contractor A, Klein WL, et al. Deleterious effects of amyloid beta oligomers acting as an extracellular scaffold for mGluR5. Neuron. 2010;66:739-54. [cited 2017 Nov 15] Available from: http://linkinghub.elsevier.com/retrieve/pii/S0896627310003223

10. Sokol DK, Maloney B, Long JM, Ray B, Lahiri DK. Autism, Alzheimer disease, and fragile $X:$ APP, FMRP, and mGluR5 are molecular links. Neurology. 2011; 76:1344-52. [cited 2017 Nov 15] Available from: http://www.neurology.org/ cgi/doi/10.1212/WNL.0b013e3182166dc7

11. Hamilton A, Esseltine JL, DeVries RA, Cregan SP, SSG F. Metabotropic glutamate receptor 5 knockout reduces cognitive impairment and pathogenesis in a mouse model of Alzheimer's disease. Mol. Brain. 2014;7:40. [cited 2016 Oct 19] Available from: http://www.ncbi.nlm.nih.gov/pubmed/24886239

12. Hamilton A, Vasefi M, Vander Tuin C, RJ MQ, Anisman H, SSG F. Chronic pharmacological mGluR5 inhibition prevents cognitive impairment and reduces pathogenesis in an Alzheimer disease mouse model. Cell Rep. 2016; 15:1859-65. [cited 2016 Oct 19] Available from: http://www.ncbi.nlm.nih. gov/pubmed/27210751

13. Ribeiro FM, Devries RA, Hamilton A, Guimaraes IM, Cregan SP, Pires RGW, et al. Metabotropic glutamate receptor 5 knockout promotes motor and biochemical alterations in a mouse model of Huntington's disease. Hum Mol Genet. 2014;23:2030-42. [cited 2016 Oct 19] Available from: http:// www.ncbi.nlm.nih.gov/pubmed/24282028

14. Abd-Elrahman KS, Hamilton A, Hutchinson SR, Liu F, Russell RC, SSG F. mGluR5 antagonism increases autophagy and prevents disease progression in the zQ175 mouse model of Huntington's disease. Sci Signal. 2017;10: eaan6387. [cited 2018 Jan 30] Available from: http://www.ncbi.nlm.nih.gov/ pubmed/29259100 
15. Ganley IG, Lam DH, Wang J, Ding X, Chen S, Jiang X. ULK1.ATG13.FIP200 complex mediates mTOR signaling and is essential for autophagy. J Biol Chem. 2009;284:12297-305. [cited 2017 Aug 3] Available from: http://www. ncbi.nlm.nih.gov/pubmed/19258318. American Society for Biochemistry and Molecular Biology

16. Lindemann $L$, Jaeschke $G$, Michalon A, Vieira E, Honer M, Spooren W, et al. CTEP: a novel, potent, long-acting, and orally bioavailable metabotropic glutamate receptor 5 inhibitor. J Pharmacol Exp Ther. 2011;339:474-86. [cited 2016 Oct 21] Available from: http://www.ncbi. nlm.nih.gov/pubmed/21849627

17. Quiroz JA, Tamburri P, Deptula D, Banken L, Beyer U, Rabbia M, et al. Efficacy and safety of basimglurant as adjunctive therapy for major depression. JAMA Psychiatry. 2016;73:675. [cited 2016 Nov 15] Available from: http://archpsyc.jamanetwork.com/article.aspx?doi=10.1001/ jamapsychiatry.2016.0838

18. Zhang T, Dong K, Liang W, Xu D, Xia H, Geng J, et al. G-protein-coupled receptors regulate autophagy by ZBTB16-mediated ubiquitination and proteasomal degradation of Atg14L. elife. 2015;4:e06734. [cited 2016 Oct 21] Available from: http://www.ncbi.nlm.nih.gov/pubmed/25821988

19. EYW C, Kir S, Tooze SA. siRNA screening of the kinome identifies ULK1 as a multidomain modulator of autophagy. J Biol Chem. 2007;282:25464-74. [cited 2017 Aug 3] Available from: http://www.jbc.org/lookup/doi/10.1074/ jbc.M703663200

20. Hara T, Takamura A, Kishi C, lemura S, Natsume T, Guan J-L, et al. FIP200, a ULK-interacting protein, is required for autophagosome formation in mammalian cells. J Cell Biol. 2008;181:497-510. [cited 2017 Aug 3] Available from: http://www.jcb.org/lookup/doi/10.1083/jcb.200712064

21. Page G, Khidir FAL, Pain S, Barrier L, Fauconneau B, Guillard O, et al. Group I metabotropic glutamate receptors activate the p70S6 kinase via both mammalian target of rapamycin (mTOR) and extracellular signal-regulated kinase (ERK 1/2) signaling pathways in rat striatal and hippocampal synaptoneurosomes. Neurochem Int. 2006;49:413-21. [cited 2017 Aug 3] Available from: http://linkinghub.elsevier.com/retrieve/pii/ S019701860600088X

22. Hara T, Nakamura K, Matsui M, Yamamoto A, Nakahara Y, Suzuki-Migishima $R$, et al. Suppression of basal autophagy in neural cells causes neurodegenerative disease in mice. Nature. 2006;441:885-9. [cited 2017 Nov 15] Available from: http://www.ncbi.nlm.nih.gov/pubmed/16625204

23. Orr ME, Oddo S. Autophagic/lysosomal dysfunction in Alzheimer's disease. Alzheimers Res Ther. 2013;5:-53. [cited 2017 Nov 15] Available from: http:// www.ncbi.nlm.nih.gov/pubmed/24171818

24. Sarkar S, Rubinsztein DC. Small molecule enhancers of autophagy for neurodegenerative diseases. Mol BioSyst. 2008;4:895-901. [cited 2017 Jan 11] Available from: http://xlink.rsc.org/?DOI=b804606a

25. Rubinsztein DC, DiFiglia M, Heintz N, Nixon RA, Qin Z-H, Ravikumar B, et al, Autophagy and its possible roles in nervous system diseases, damage and repair. Autophagy. 2005;1:11-22. [cited 2017 Nov 15] Available from: http:// www.ncbi.nlm.nih.gov/pubmed/16874045

26. Nah J, Yuan J, Jung Y-K. Autophagy in neurodegenerative diseases: from mechanism to therapeutic approach. Mol Cells. 2015;38:381-9. [cited 2018 Mar 7] Available from: http://www.ncbi.nlm.nih.gov/pubmed/25896254. Korean Society for Molecular and Cellular Biology

27. Nixon RA. The role of autophagy in neurodegenerative disease. Nat Med. 2013;19:983-97. [cited 2018 Mar 7] Available from: http://www.nature.com/ articles/nm.3232. Nature Publishing Group

28. Lee K-M, Hwang S-K, Lee J-A. Neuronal autophagy and neurodevelopmental disorders. Exp Neurobiol. 2013;22:133. [cited 2018 Feb 2] Available from: https://synapse.koreamed.org/DOlx.php?id=10.5607/en.2013.22.3.133

29. Sokol DK, Maloney B, Long JM, Ray B, Lahiri DK. Autism, Alzheimer disease, and fragile $X$ : APP, FMRP, and mGluR5 are molecular links. Neurology. 2011; 76:1344-52. [cited 2018 Feb 2] Available from: http://www.ncbi.nlm.nih.gov/ pubmed/21482951. American Academy of Neurology

30. Jankowsky JL, Fadale DJ, Anderson J, Xu GM, Gonzales V, Jenkins NA, et al. Mutant presenilins specifically elevate the levels of the 42 residue beta-amyloid peptide in vivo: evidence for augmentation of a 42specific gamma secretase. Hum Mol Genet. 2004;13:159-70. [cited 2018 Feb 1] Available from: https://academic.oup.com/hmg/article-lookup/doi/ 10.1093/hmg/ddh019

31. Lu YM, Jia Z, Janus C, Henderson JT, Gerlai R, Wojtowicz JM, et al. Mice lacking metabotropic glutamate receptor 5 show impaired learning and reduced CA1 long-term potentiation (LTP) but normal CA3 LTP. J Neurosci.
1997;17:5196-205. [cited 2018 Feb 1]Available from: http://www.ncbi.nlm. nih.gov/pubmed/9185557

32. Oddo S, Caccamo A, Shepherd JD, Murphy MP, Golde TE, Kayed R, et al. Triple-transgenic model of Alzheimer's disease with plaques and tangles: intracellular Abeta and synaptic dysfunction. Neuron. 2003;39:409-21. [cited 2018 Feb 1] Available from: http://www.ncbi.nlm.nih.gov/pubmed/12895417

\section{Submit your next manuscript to BioMed Central and we will help you at every step:}

- We accept pre-submission inquiries

- Our selector tool helps you to find the most relevant journal

- We provide round the clock customer support

- Convenient online submission

- Thorough peer review

- Inclusion in PubMed and all major indexing services

- Maximum visibility for your research

Submit your manuscript at www.biomedcentral.com/submit
Biomed Central 